8.P5

\title{
Development and Integration of Intrastriatal Striatal Grafts Implanted Into Long-Term Ibotenate Lesions
}

\author{
J.L. Labandeira-García ${ }^{1}$ and K. Wictorin ${ }^{2}$ \\ ${ }^{1}$ Department of Morphological Sciences, Faculty of Medicine, University of Santiago de Compostela, Spain \\ ${ }^{2}$ Department of Medical Cell Research, University of Lund, Biskopsgatan 5, S-223 62, Sweden
}

It is well known that fetal striatal tissue grafted into excitotoxically lesioned adult striatum can partially restore the behavioural / $1 /$ and biochemical $/ 3 /$ deficits, and establish anatomical connections with the host tissue /2,46/. Those previous studies were undertaken after grafting in acutely (usually 1 - 4 weeks before) lesioned striatum. Several factors change in the lesioned area after a long time of evolution. However, the capacity of survival and anatomical integration with the host of striatal grafts implanted in chronically lesioned striatum has not been investigated. In this study the development, and afferent and efferent innervation of striatal grafts implanted in longterm lesioned striatum were studied and compared with that observed in our previous studies of grafts implanted in non-lesioned or acutely lesioned host striatum $/ 2,4-6 /$.

A total of 46 female Sprague-Dawley rats received unilateral intrastriatal injections of ibotenic acid. Three to twenty months later 33 of these rats were grafted with rat or mouse fetal striatal tissue into the same area. The transplanted rats were killed at 7 days, 2 weeks (mouse-to-rat grafts only), 4 - 6 weeks, 8 weeks and 11 weeks (mouse-to-rat grafts only), 7 months and 12 months post grafting (p,g). Seven rats were lesioned but not transplanted, and sacrificed 6-12 months after the lesion. Finally, 6 acutely (10 days) lesioned rats grafted with the same cell suspension as 8 of the chronically lesioned rats were used as a control group.

DARPP-32-immunocytochemistry was used to differentiate the striatum-like and nonstriatum-like tissue-types in the grafts $16 /$. Tyrosine hydroxylase (TH) and serotonin (5HT) immunostaining was used to study the afferents from the substantia nigra and the mesencephalic raphe, respectively. Frontal cortical injections of the anterograde tracer Phaseolus vulgaris-leucoagglutinin (PHA-L) were made to study the cortico-striatal afferents to the grafts /4/. Finally, a mouse specific neuronal marker (M6) was used in mouse-to-rat grafts to study the efferent projections to the host brain from the striatal grafts $15 /$.

There was an important shrinkage of the lesioned striatum, and the centre of the lesion was composed of capsula interna bundles close to each other and separated by thin bridges of non-neuronal striatal tissue. The density of the host monoaminergic fibres ( $\mathrm{TH}-$ and $5-\mathrm{HT}$ positive fibres) in the lesion-only areas or at the graft-host torder was not much reduced, as compared with the acute-lesion controls. In contrast, the cortical innervation was much reduced in long-term lesioned striatum, at the same time that a dense network of PHA-L labelled corticostriatal fibres was observed in the contralateral striatum.

The transplants grew to about $70-80 \%$ of the size obtained with control grafts placed into acute lesions, and developed characteristic striatum-like (i.e. DARPP-32-positive) patches. These patches could already be observed in the grafts 7 days after transplantation, i.e. as early as in grafts implanted in acute lesions. The grafts received a dense dopaminergic innervation, which was selective for the striatal-like areas, and began as early as in grafts implanted in acute lesions. The 5-HT-positive fibres also innervated the transplant following a pattern similar to that observed in grafts implanted into acute excitotoxic lesions. As the cortical innervation appeared much degenerated, the 
cortical innervation of implants placed in longterm lesioned striatum was poor, particularly in the most chronic lesions. The cross-species experiments also showed that implants placed into chronic lesions were projecting into the host tissue.

It is concluded that intrastriatal striatal grafts can develop striatum-like regions and establish afferent and efferent connections with the host brain, also when implanted into chronic lesions. These grafts become well innervated by monoaminergic afferents, but the progressive decrease in the density of the cortico-striatal afferents to the long-term lesioned striatum notably restricts the amount of cortical innervation that such grafts receive.

\section{REFERENCES}

1. Dunnett $S B$, Isacson $O$, Sirinathsinghji DJS, Clarke DJ, Björklund A. Neuroscience 1988; 24: 813-820.

2. Labandeira-García JL, Wictorin $\mathrm{K}$, Cunningham ET, Björklund A. Neuroscience 1991; 42: 407-426.

3. Sirinathsinghji DJS, Dunnett SB, Isacson O, Clarke DJ, Kendrick K, Björklund A. Neuroscience 1988; 24: 803811.

4. Wictorin K, Björklund A. Neuroscience 1989; 30: 297 311.

5. Wictorin K, Lagenaur CF, Lund RD, Björklund A. Eur J Neurosci 1991; 3: 86-101.

6. Wictorin K, Ouimet CC, Björklund A. Eur J Neurosci 1989; 1: 690-701. 

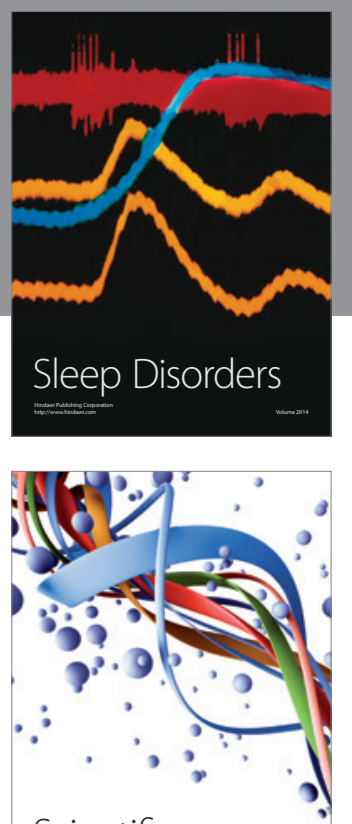

Scientifica
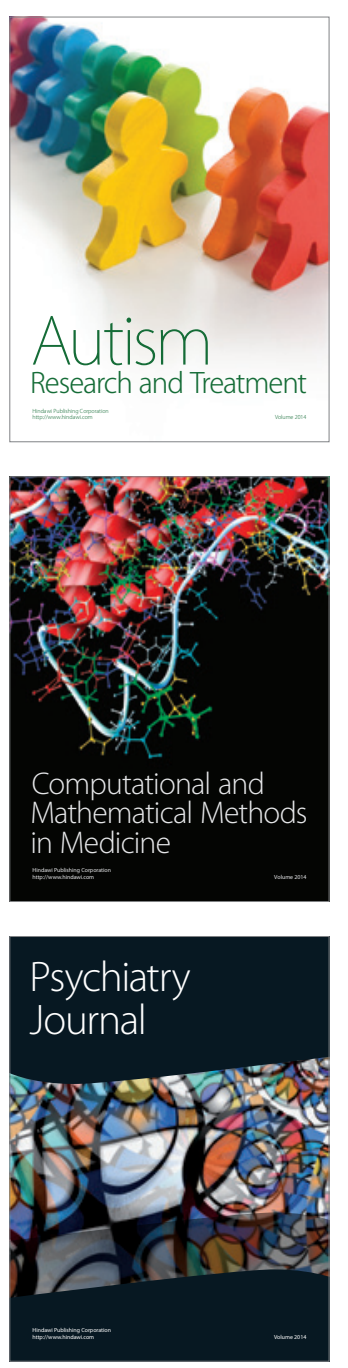
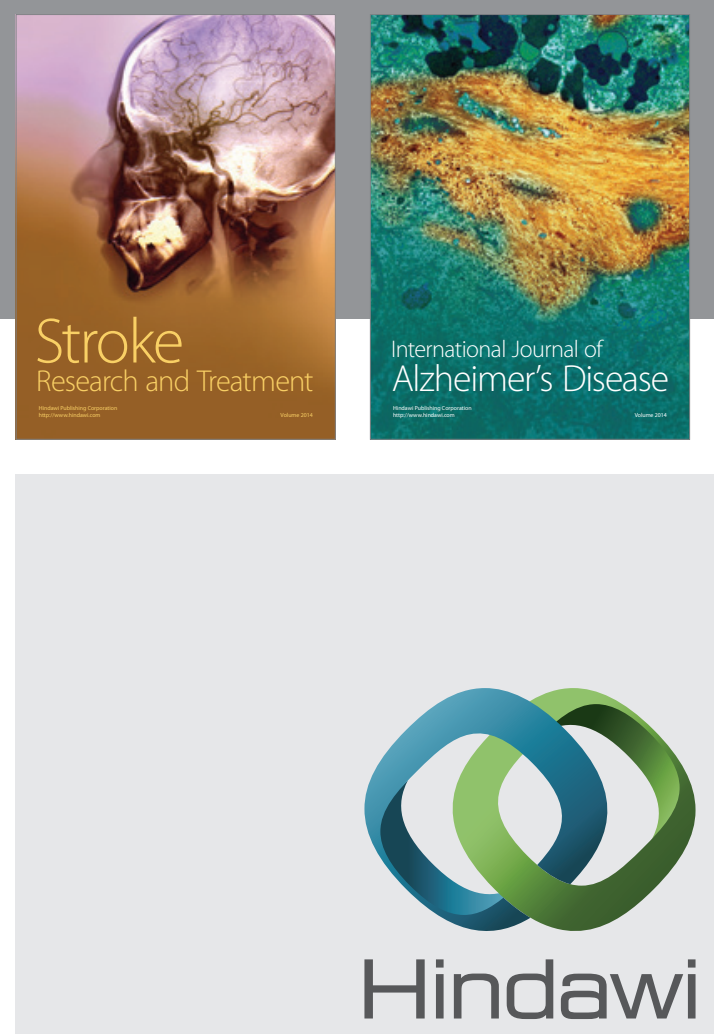

Submit your manuscripts at

http://www.hindawi.com
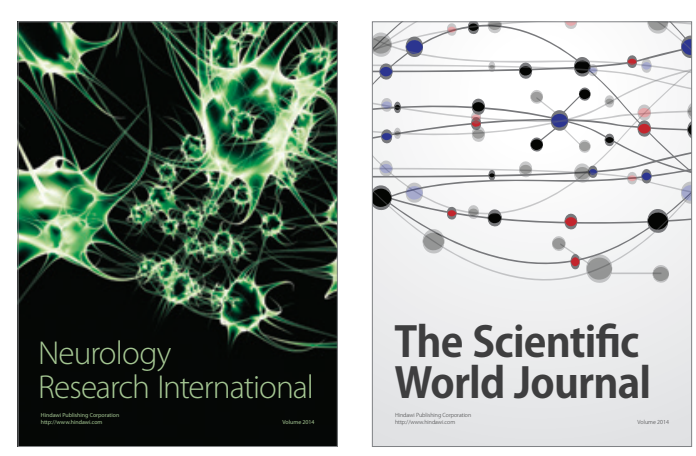

The Scientific World Journal

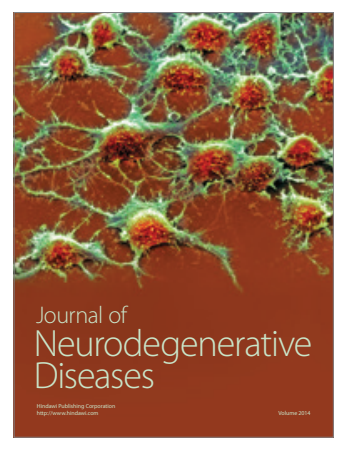

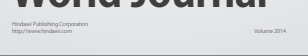

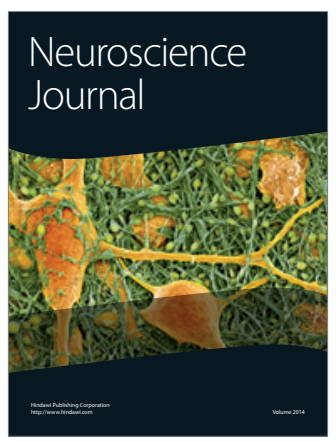

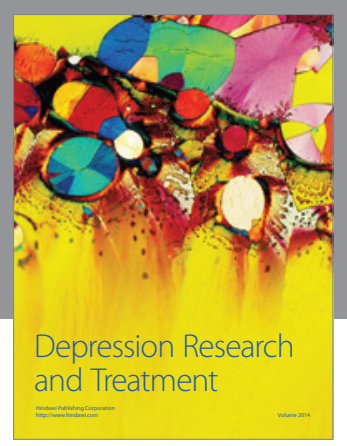
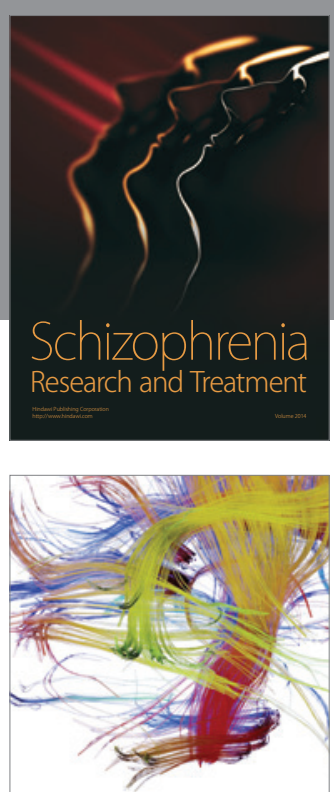

Brain Science

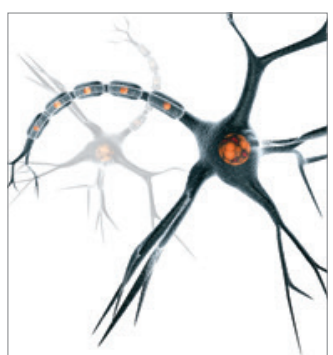

Neural Plasticity
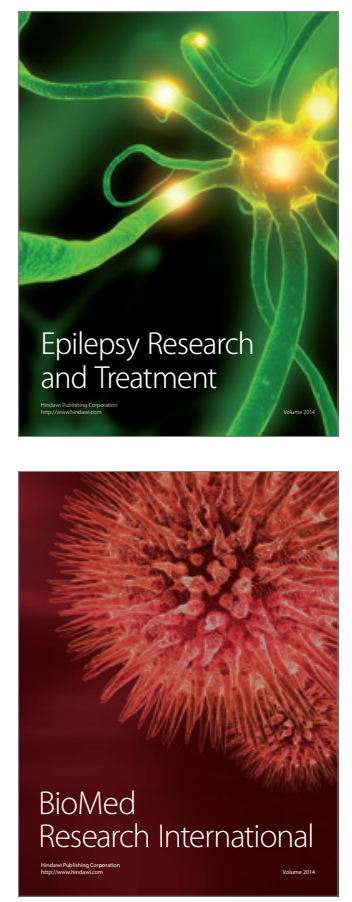

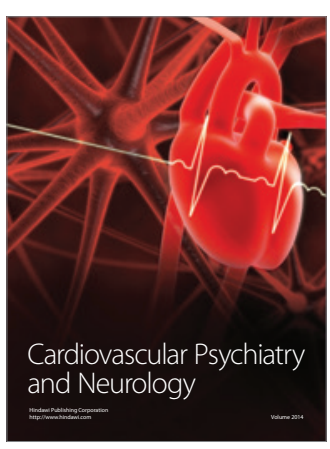

Parkinson's

Disease
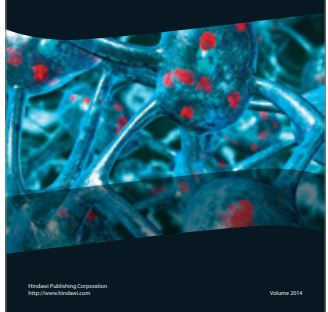